\title{
GENETIC (RAPD-PCR) VARIABILITY OF STAPHYLOCOCCUS AUREUS STRAINS EXTRACTED FROM LOCUS MORBI AND INTAKT SKIN OF PATIENTS WITH ALLERGODERMATOSIS
}

\author{
Sergiy Pokhil \\ Laboratory of New and Little-Explored Infections Disease \\ $S E$ «I. Mechnikov Institute of Microbiology and Immunology of \\ the National Academy of Medical Sciences of Ukraine» \\ 14-16 Pushkinskay str., Kharkiv, Ukraine, 61057 \\ pokhil_kharkiv@ukr.net \\ Svetlana Dzhoraeva \\ Laboratory and Experimental Department \\ SE «Institute of Dermatology and Venerology of \\ the National Academy of Medical Sciences of Ukraine» \\ 7/9 Chernyshevka str., Kharkiv, Ukraine, 61057 \\ sjoraeva@i.ua
}

\begin{abstract}
The article presents data on the study of genetic relatedness of $S$. aureus strains growing on the skin and nasal passages of patients with allergodermatoses. A study of the possible correlation between the genotype of the pathogen and the burden of allergodermatoses using the RAPD-PCR method was done.

The aim of the research: determination by RAPD-PCR analysis (Random Amplified Polymorphic DNA) of genetic variability and affinity of $S$. aureus strains extracted from locus morbi, intact areas of skin and nasal mucosa of patients with allergodermatoses (AD and IE).

Materials and methods. RAPD-PCR was used to genotype 111 strains of Staphylococcus aureus extracted from the skin and nasal passages of patients with allergodermatoses (AD and IE), as well as 11 strains isolated from the skin of almost healthy individuals to identify genetic links between these strains. These strains were removed from patients with AD and IE who sought medical help in the dermatological department of the State Institution "Institute of Dermatology and Venereology of the National Academy of Medical Sciences of Ukraine" during 2016-2019.

Results. When comparing the RAPD spectra of strains extracted from the affected and intact areas of the skin of patients with mild and severe $\mathrm{AD}$, the degree of genetic relatedness of the strains was $75.1 \pm 4.4 \%$ and $98.8 \pm 0.8 \%$, ( $\mathrm{p}<0,001)$, respectively, indicating a high level of affinity of the strains. Strains of S. aureus removed from the nasal passages of patients with AD had a high level of genetic affinity with strains removed from the affected areas of the skin $-79.5 \pm 1.6 \%$, which indicates the auto-origin of strains growing on the skin of patients. The affinity of strains isolated from patients with IE with the reference culture of $S$. aureus ATCC 25923 was $27.4 \pm 1.8 \%$ and $52.0 \pm 5.2 \%$ for strains isolated from patients with AD, indicating their low genetic relatedness.

Conclusions. In the study of RAPD spectra of S. aureus strains isolated from patients with both AD and IE, no genotype was identified that would be associated with the disease or its severity. A high level of genetic affinity of strains extracted from locus morbi with strains extracted from the nasal passages of patients with $\mathrm{AD}$, indicating the auto-origin of strains that grow on the skin of patients. It is shown that with increasing severity of $\mathrm{AD}$, the genetic monotype of isolated pathogens increased: in patients with mild AD, 3 genetic clusters of the microorganism were identified, with moderate - 2, and with severe only one.
\end{abstract}

Keywords: clinical strains of staphylococci, allergic dermatitis, RAPD-PCR.

DOI: $10.21303 / 2504-5679.2020 .001312$

\section{Introduction}

Atopic dermatitis (AD) and idiopathic eczema (IE) are the most common allergic skin diseases (allergodermatoses) that arise and develop due to a complex set of exogenous and endogenous etiological factors and mechanisms of pathogenesis, among which the leading role is played by skin barrier dysfunction and disorders of immunological reactivity. In recent years, these allergodermatoses tend to more severe clinical course with the development of complications, chronicity of 
the pathological process, frequent relapses, resistant to standard treatments, which is the cause of long-term disability, reduced quality of life and social activity [1].

Currently, there is a sufficient amount of work on the role of Staphylococcus aureus in the burden of $\mathrm{AD}[2,3]$. It is known that under the conditions of unprofitable colonization $S$. aureus expels commensal bacteria from the skin, while its pathogenic factors have a negative impact on the integrity of the epithelial barrier and the functioning of the immune system. Therefore, according to some authors, $S$. aureus is not only a secondary factor in the exacerbation of AD, but also one of the causes of exacerbations [4].

Previous studies have shown differences in a number of phenotypic traits of $S$. aureus strains that colonize the affected and intact areas of the skin of patients with allergodermatoses [5-7]. In this case, the density of skin colonization of patients in the locus morbi directly correlates with the severity of these diseases. In addition, the values of certain pathogenicity factors in $S$. aureus strains removed from the lesions of the skin of patients significantly exceeded similar values in strains isolated from intact areas of the skin of patients and a group of healthy individuals. However, to date there are no data in the literature on the authenticity (probable genetic relatedness) of $S$. aureus strains that grow in different areas of the skin of patients with allergodermatoses, and in the main biotope of these microorganisms - the nasal mucosa of the host. An important scientific task is to study the relationship between the genotypes of strains of $S$. aureus isolated from patients with allergodermatoses and the severity of the disease.

The aim of the research: determination by RAPD-PCR analysis (Random Amplified Polymorphic DNA) of genetic variability and affinity of $S$. aureus strains extracted from locus morbi, intact areas of skin and nasal surface of patients with allergodermatoses (AD and IE).

\section{Materials and methods}

Isolation and identification of $S$. aureus strains from patients with allergodermatoses who received medical care in the dermatological department of the Institute of Dermatology and Venereology of the National Academy of Medical Sciences of Ukraine during 2016-2019, carried out classical bacteriological methods according to international protocols and regulations of the Ministry of Health of Ukraine [8, 9].

In total, 122 strains of $S$. aureus were genotyped by RAPD-PCR, among which: 55 were removed from patients with $\mathrm{AD}$ ( 33 - from foci of skin lesions and 22 - from its intact areas), 43 from patients with IE (33 - from foci lesions and 10 - from intact skin areas), 12 - from the nasal mucosa of a group of patients with allergodermatoses, 11 - from intact skin areas of almost healthy individuals and the reference (typical) strain of S. aureus ATCC 25923.

Isolation of DNA of $S$. aureus strains and its RAPD-PCR analysis. DNA isolation of S. aureus isolates was performed using the Diatom ${ }^{\text {TM }}$ DNAPrep 2000 (RF) kit according to the kit manufacturer's instructions. Primers OLP6 (5'-GAGGGAAGAG-3'), OLP11 (5'-ACGATGAGCC-3') and OLP13 (5'-ACCGCCTGCT-3') were used to play RAPD-PCR, as described in [10-13], and

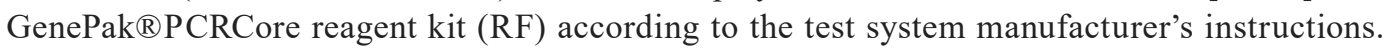
Amplification program: initial denaturation at $94{ }^{\circ} \mathrm{C}$ for $5 \mathrm{~min}$ followed by 40 cycles of denaturation at $93{ }^{\circ} \mathrm{C}$ for $1 \mathrm{~min}$, annealing at $37{ }^{\circ} \mathrm{C}$ for $1.5 \mathrm{~min}$, elongation at $72{ }^{\circ} \mathrm{C}$ for $1 \mathrm{~min}$ and with terminal elongation for $7 \mathrm{~min}$ at $72{ }^{\circ} \mathrm{C}$. A positive control was a reaction mixture containing chromosomal DNA of the reference strain $S$. aureus ATCC 25923, and as a negative control the same mixture without added DNA. Positive and negative controls were included in each run. All S. aureus strains were tested under the same conditions, each of them at least twice. For imaging, the amplified DNA fragments were subjected to electrophoresis in $1.5 \%$ agarose gel in TBE buffer containing $0.5 \mu \mathrm{g} / \mathrm{ml}$ ethidium bromide at a constant electric field voltage of $4 \mathrm{~V} / \mathrm{cm}$ for 40 minutes. RAPD-PCR products were analysed using a molecular weight marker of DNA M-Combi (RF), containing DNA fragments of sizes 50, 100, 150, 200, 250, 300, 350, $400,500,600,700,800,900,1000,1200,1400,1600,1800$, and 2000 nucleotide pairs (bp). DNA fragments formed using OLP6 and OLP11 primers range in size from 100 to $1200 \mathrm{bp}$, and using OLP13 primer from 300 to 2000 bp. [12, 13]. Genetic polymorphism and affinity of S. aureus strains were evaluated by the similarity/difference of the obtained RAPD-PCR profiles (a set 
of bands on electrophoresis tracks forming patterns), which are generated by each primer and their combination. The degree of similarity between RAPD-PCR profiles was determined by the forula:

$$
\frac{2 N x y}{N x+N y} \times 100 \% \text {, }
$$

where $N x y$ - the number of matching bands on the compared patterns $x$ and $y ; N x$ and $N y-$ the total number of bands on the patterns $\mathrm{x}$ and $\mathrm{y}$.

$S$. aureus strains were assigned to one genotype at a level of similarity of RAPD-PCR profiles $\geq 70 \%$, which indicates the probability of their relationship by origin $[13,14]$. Strains were considered genetically monotypic if their patterns had the same number of bands and the corresponding bands had the same visual size.

\section{Results}

One of the methods used to study the structure of the population of microorganisms is the method of RAPD-PCR analysis (Random Amplified Polymorphic DNA). The RAPD method is based on PCR amplification of random DNA regions using one or more, usually short (up to 10 pairs of nucleotide bases) primers of arbitrary sequence, which induce in each reaction the synthesis of several dozen DNA fragments of random localization [14, 16]. By differences in the reaction products - RAPD spectra - which are DNA fragments of different lengths, it is possible to register differences between the genomes of closely related microorganisms. The ability to study the polymorphism of the entire genome without prior knowledge of specific DNA sequences is the main advantage of RAPD analysis [12, 17]. The high level of polymorphism, which is determined by RAPD-PCR method, is quite informative in population studies to detect latent genetic polymorphism in lines and related species, as well as individual identification $[18,19]$.

In Fig. 1-3 there are electrophoregrams of RAPD-PCR patterns (generated by primers OLP6, OLP11 and OLP13) of S. aureus strains isolated from patients with AD with mild (S1-S10), moderate (S11-S21) and severe (S22-S33) disease, respectively.

To determine the genetic relatedness of strains growing in the lesions and intact skin of patients with $\mathrm{AD}$, a comparison of genetic traits of strains removed from locus morbi and intact areas of skin of patients with mild and severe AD (comparison was performed with strains removed from one and the same patient). The obtained data are shown in Fig. 4, 5.

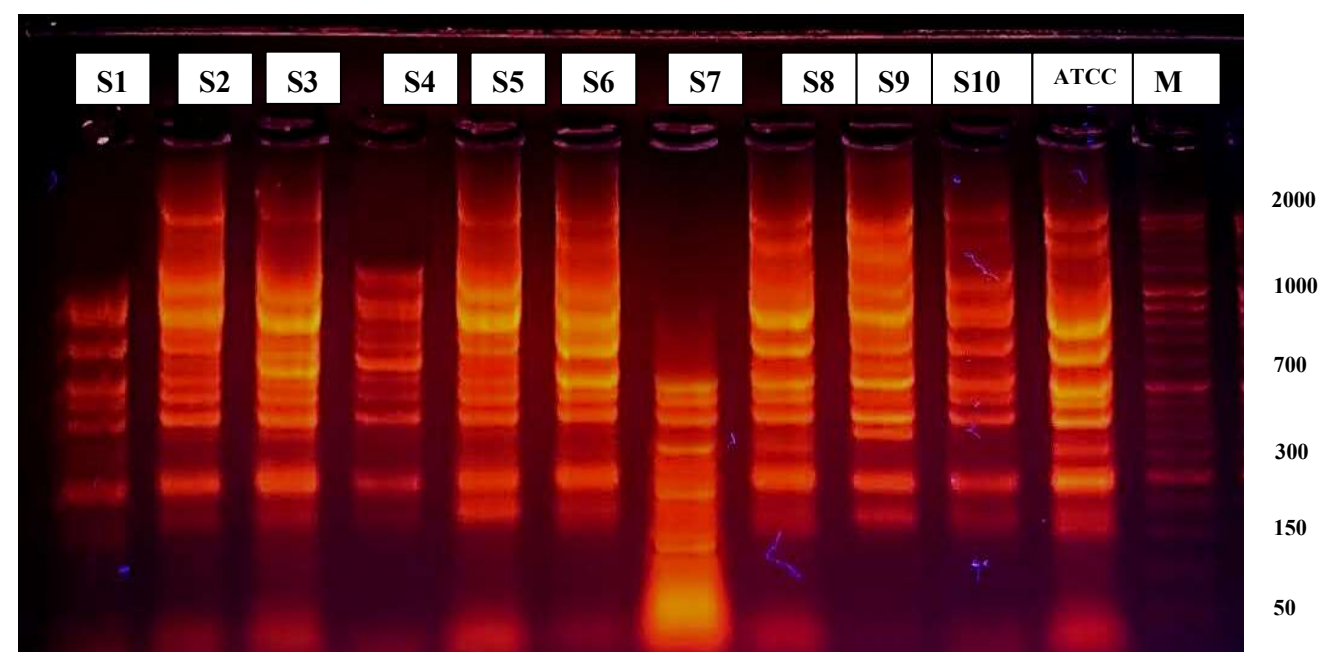

Fig. 1. RAPD-PCR patterns of $S$. aureus strains isolated from patients with mild AD (S1-S10) and reference strain S. aureus ATCC 25923 (ATCC); M-Combi DNA molecular weight marker (M) 


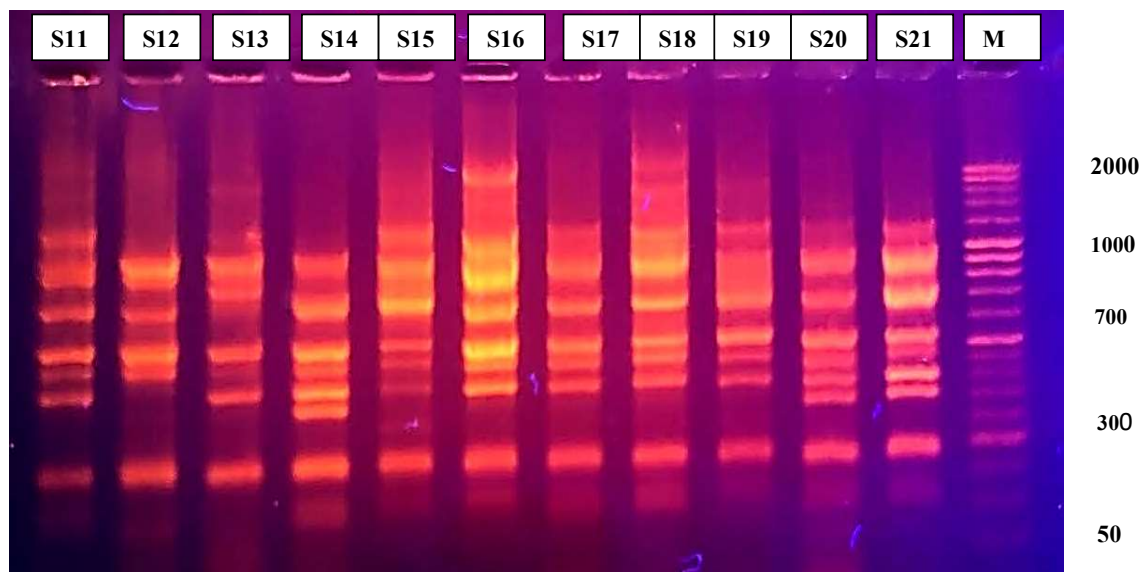

Fig. 2. RAPD-PCR patterns of $S$. aureus strains isolated from patients with moderate AD (S11-S21) and reference strain S. aureus ATCC 25923 (ATCC); M-Combi DNA molecular weight marker (M)

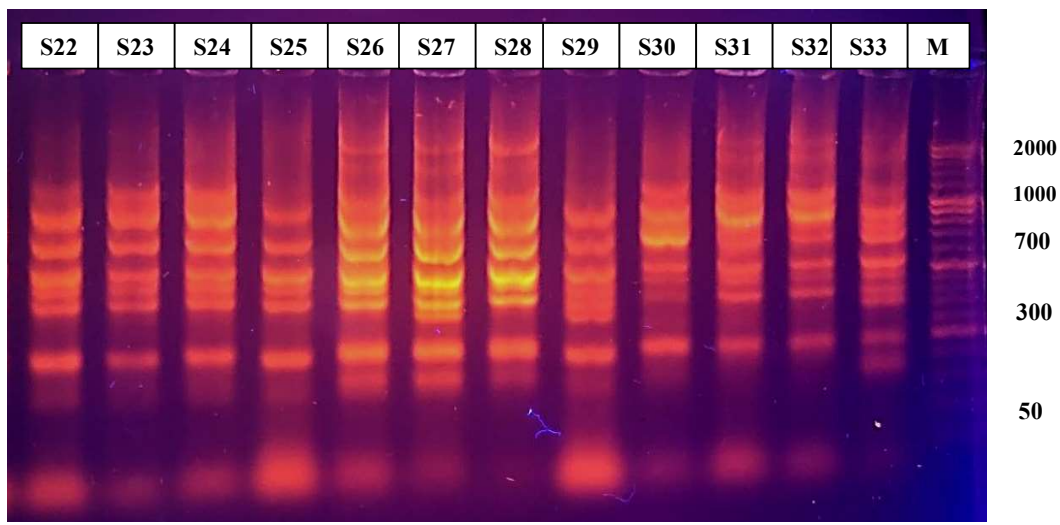

Fig. 3. RAPD-PCR patterns of S. aureus strains isolated from patients with severe AD (S22-S33) and reference strain S. aureus ATCC 25923 (ATCC); M-Combi DNA molecular weight marker (M)

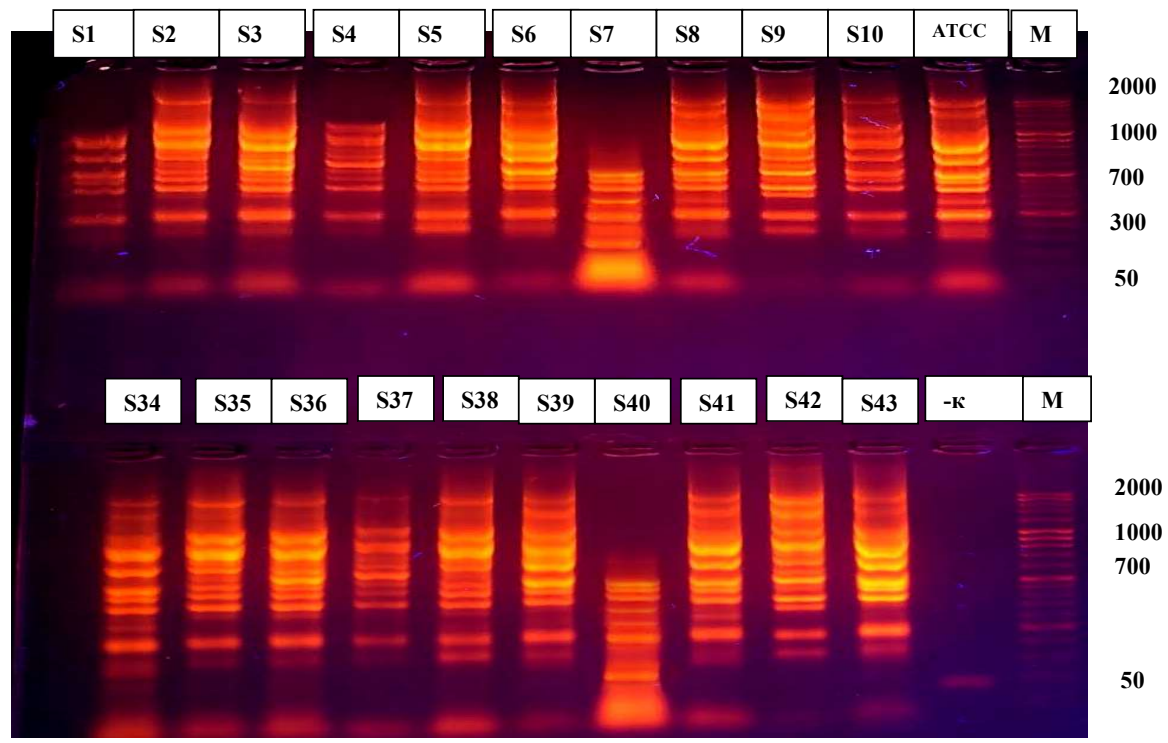

Fig. 4. RAPD-PCR patterns of $S$. aureus strains extracted from locus morbi (S1-S10), intact skin areas of patients with AD (S34-S43) and reference strain S. aureus ATCC 25923 (ATCC); marker molecular weight of DNA M-Combi (M). 


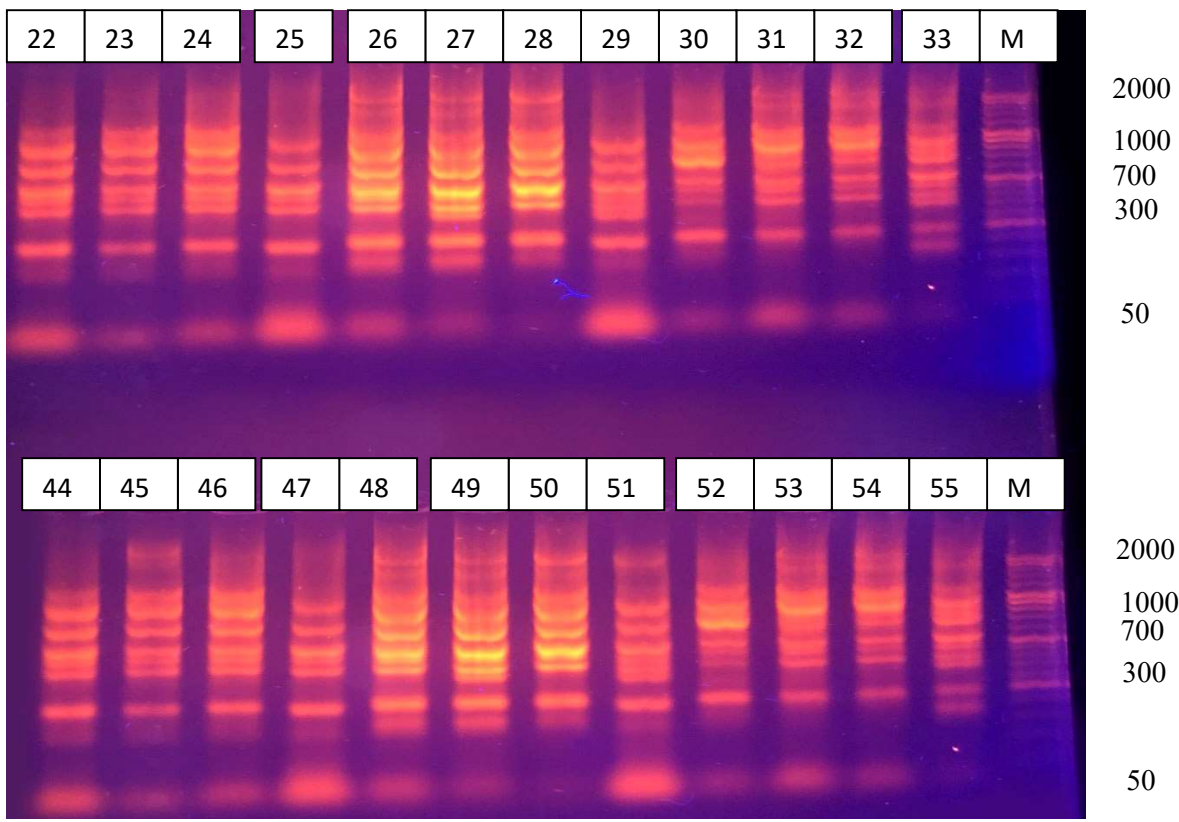

Fig. 5. RAPD-PCR pattern of $S$. aureus isolates extracted from locus morbi (S22-S33) and intact areas of skin of patients with severe AD (S44-S55) marker molecular weight DNA M-Combi (M)

In order to determine the presence of isolates inherent in the skin of patients, the genetic variability of $S$. aureus strains extracted from the skin of almost healthy individuals was determined. The obtained data are shown in Fig. 6.

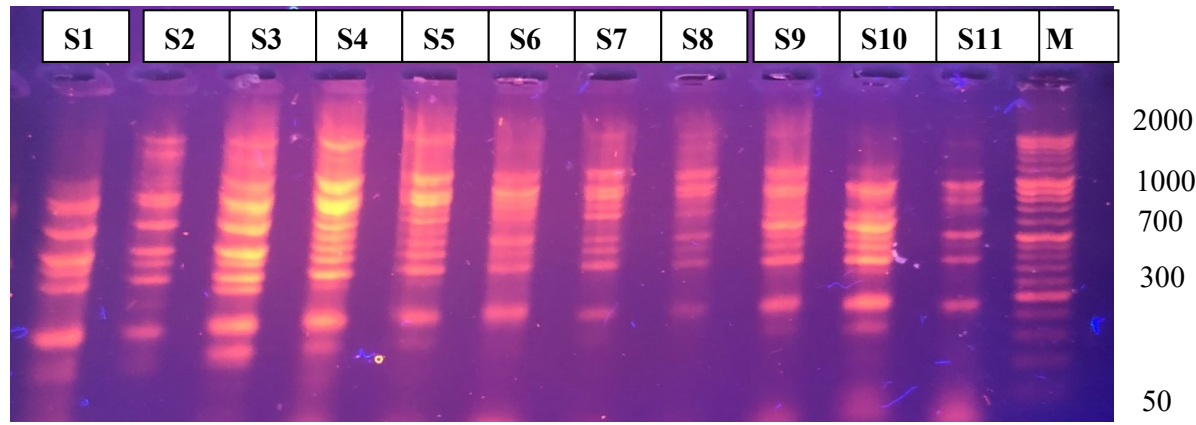

Fig. 6. RAPD-PCR patterns of $S$. aureus isolates extracted from the skin of healthy individuals (S1-S11), DNA molecular weight marker M-Combi (M)

It is known that in most patients with $\mathrm{AD}$, especially with severe course, $S$. aureus is removed not only from the skin but also from the nasal passages [4], so the next step was to study RAPD-spectra of strains extracted from the nasal passages of patients with AD and their comparison with fingerprints of $S$. aureus strains extracted from locus morbi patients with AD. The obtained data are shown in Fig. 7.

At the next stage of the study, a study of the genetic variability of $S$. aureus strains isolated from patients with IE. The obtained data are shown in Fig. 8-10.

To determine the genetic relatedness of strains growing in the lesions and intact skin of patients with IE, a comparison of genetic traits of strains removed from locus morbi and intact areas of skin of patients with moderate to severe IE (comparison was made with strains removed from one and the same patient). The obtained data are shown in Fig. 11. 


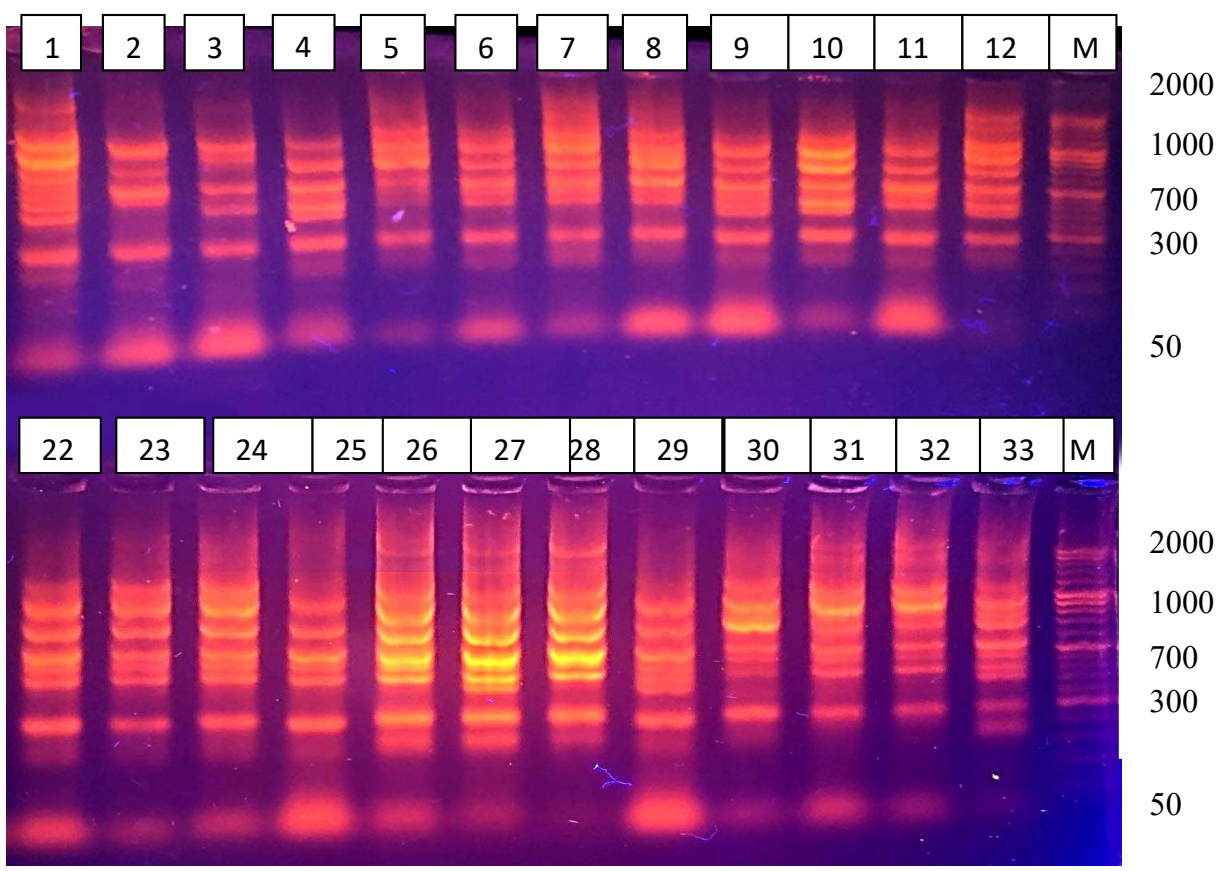

Fig. 7. RAPD-PCR pattern of $S$. aureus isolates extracted from nasal passages (S1-S12) and affected skin areas (S22-S32) of patients with severe AD, M-Combi (M) DNA molecular weight marker

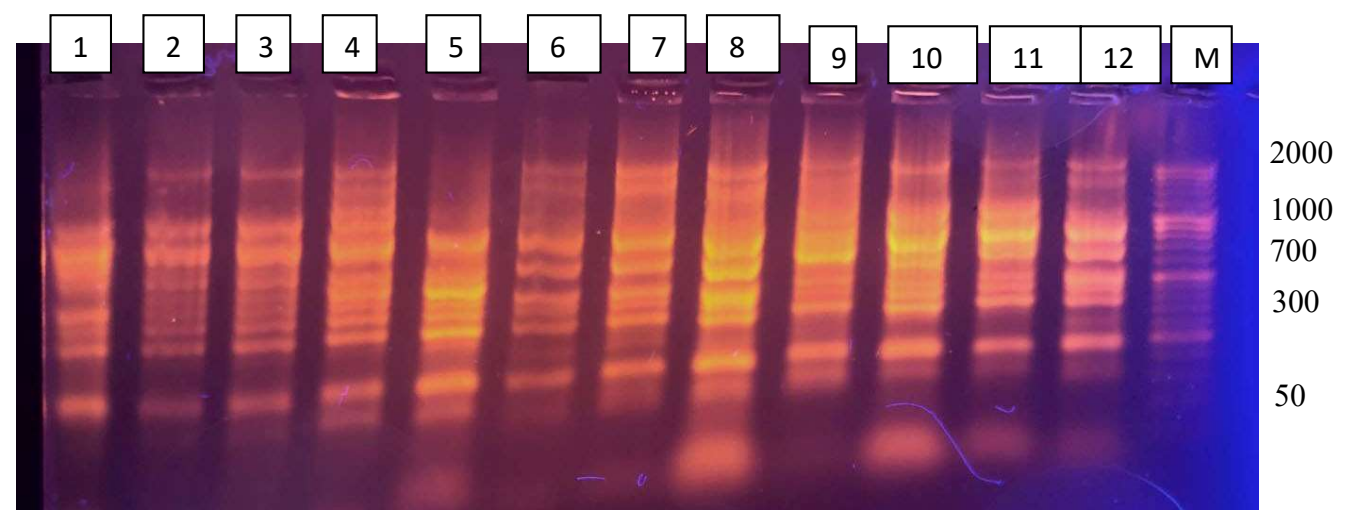

Fig. 8. RAPD-PCR patterns of $S$. aureus isolates extracted from the locus morbi of patients with mild IE (S1-S12), a marker of DNA molecular weight M-Combi (M)



Fig. 9. RAPD-PCR patterns of $S$. aureus isolates extracted from locus morbi of patients with moderate to severe IE (S13-S22), DNA molecular weight marker M-Combi (M) 


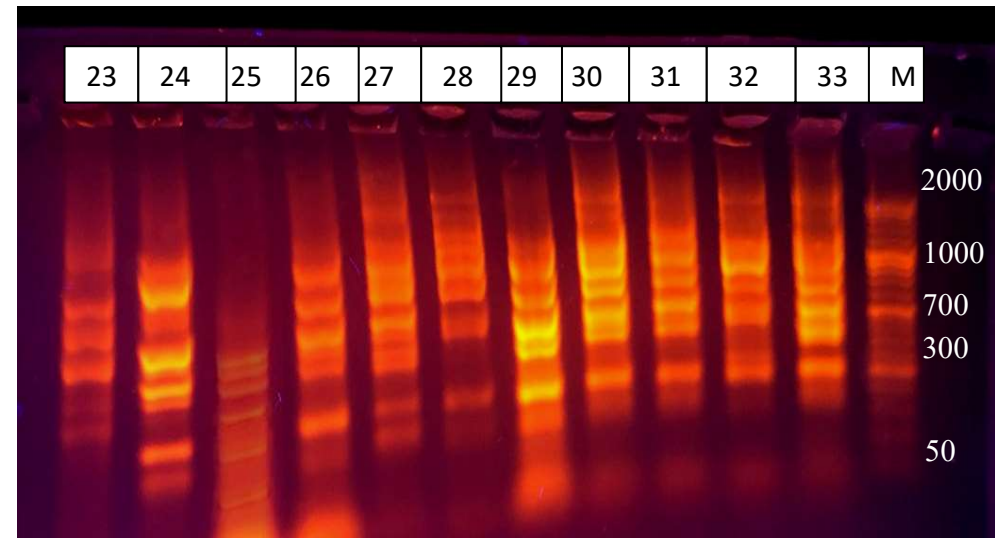

Fig. 10. RAPD-PCR patterns of $S$. aureus isolates extracted from locus morbi of patients with moderate to severe IE (S23-S33), DNA molecular weight marker M-Combi (M)

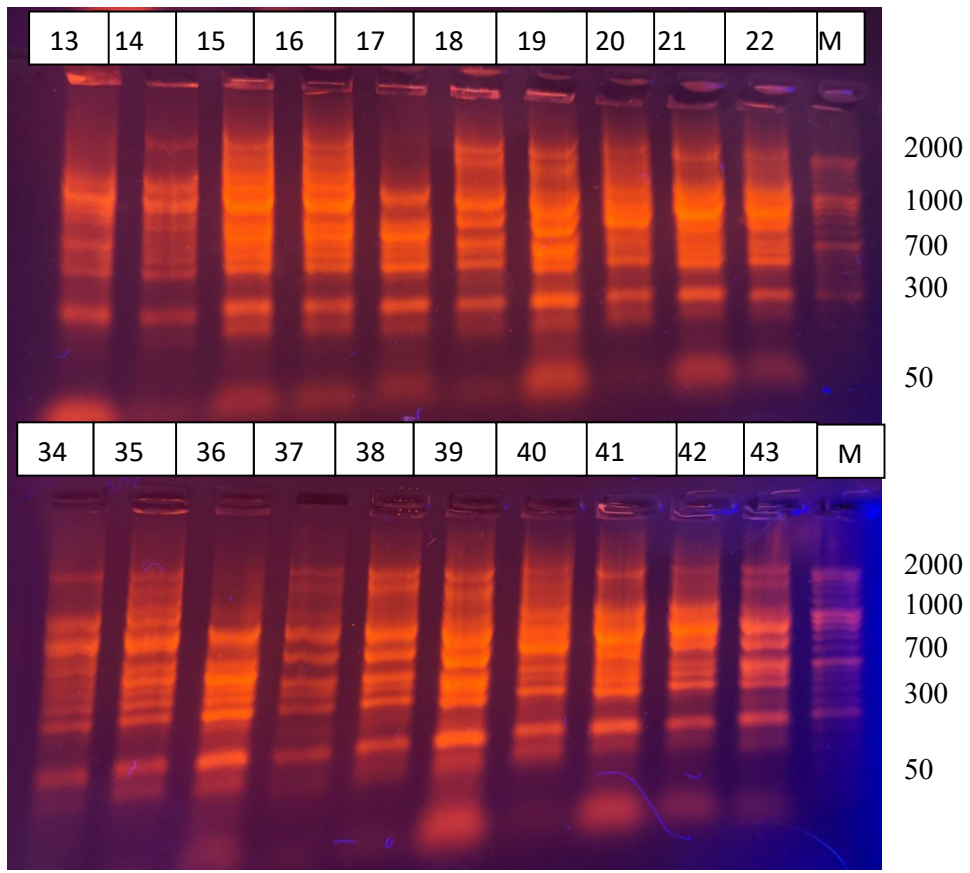

Fig. 11. RAPD-PCR pattern of $S$. aureus isolates extracted from locus morbi (S13-S22) and intact skin areas (S34-S43) of patients with moderate to severe IE, DNA molecular weight marker M-Combi (M)

\section{Discussion}

As can be seen in the electrophoregrams of Fig. 1-3, in RAPD-PCR patterns of S. aureus strains isolated from patients with varying severity of $\mathrm{AD}$, the total number of visualized bands (DNA amplicons of different sizes) ranged from 6 to 11. According to the analysis of RAPDPCR patterns of $S$. aureus S1-S10 strains (extracted from patients with mild AD) are grouped into three genetic clusters (Fig. 1): I - with the presence of amplicons ranging in size from 150 to 2000 bp. (tracks S2-S6 and S8-S10), II - 250-1200 bp (track S1) and III - 50-900 bp (track S7). Within the cluster I, the degree of similarity of RAPD-PCR patterns ranged from 66.7 to $88.9 \%$ (with an average value of $77.6 \pm 3.3 \%$ ), which allows strains of $S$. aureus S2-S6 and S $8-\mathrm{S} 10$ to be attributed to one genotype. The degree of similarity of clusters I and II was $42.9 \%$, I and III clusters - $66.7 \%$, and II and III - $66.7 \%$, which indicates a significant genetic difference between the compared strains. The RAPD-PCR profile of the reference strain S. aureus ATCC 25923 consisted of amplicons of 1800, 1600, 900, 800, 700, 600, 500, 400, 300,250 and $200 \mathrm{bp}$. (ATCC track) and has a high (70.5\%) affinity with the profile of clinical 
strain S1, slightly lower (57.1\%) with strains of cluster I and relatively low (47.1\%) with culture $\mathrm{S} 7$ of cluster III.

The analysis of electrophoregrams of laboratory isolates S34-S43 extracted from intact areas of the skin of patients with AD also identified 2 clusters of RAPD spectra: with the presence of fragments weighing from 200 to 2000 bp. (Fig. 4, row 2 tracks No. 1-6 and 8-10) and 150-900 n.p. (Fig. 4, row 2 track No. 7). The total number of fragments ranged from 6 to 11 . When comparing the first and second clusters, the degree of similarity was $53.3 \%$. The average affinity between isolates isolated from intact skin was $66.7 \pm 3.5 \%$. In the analysis of electrophoregrams of laboratory isolates S11-S21 2 clusters of RAPD spectra were isolated: with the presence of fragments weighing from 250 to 2000 bp. (Fig. 2, tracks No. 1, and 5-11) and from 250 to 900 (Fig. 2, tracks No. 2-4). The degree of similarity of RAPD spectra ranged from $53.3 \%$ to $90.0 \%$ (average $75.0 \pm 3.6 \%$ ). The degree of relatedness between these clusters was $37.5 \%$, which indicates their low genetic homogeneity. When comparing the RAPD spectra of laboratory strains with the reference culture of $S$. aureus ATCC 25923, moderate genetic affinity with strains of the first cluster$52.6 \%$ and low with culture profiles from the second cluster $-31.6 \%$ of similarity. In the analysis of electrophoregrams of laboratory isolates S22-S33, 1 cluster of RAPD spectra was identified: with the presence of fragments weighing from 2000 to 200 bp. (Fig. 3, tracks No. 1-11). The degree of similarity of RAPD spectra ranged from $62.5 \%$ to $100 \%$ (mean $80.3 \pm 3.9 \%$ ). When comparing the RAPD spectra of laboratory strains was noted with the reference culture of $S$. aureus ATCC 25923 showed a low genetic affinity with culture profiles (38.1\% of similarity).

Thus, the average variability of laboratory strains of staphylococci, classified as the most common cluster was $77.6 \pm 1.5 \%$, which indicates a high genetic relatedness among these cultures. The degree of affinity of these strains with the reference culture of S. aureus ATCC 25923 averaged $53.1 \pm 5.4 \% \%$, indicating their moderate genetic affinity.

At the next stage of the study, a comparison of RAPD spectra of laboratory strains of staphylococci extracted from the affected and intact areas of the skin of patients with mild AD was performed. The obtained data are given in Table 1.

Table 1

Comparison of fingerprints of $S$. aureus strains extracted from lesions and intact skin areas of patients with mild AD

\begin{tabular}{ccc}
\hline No. & The compared strains & The level of strains affinity \\
\hline 1 & $\mathrm{~S} 1-\mathrm{S} 34$ & $47.1 \%$ \\
2 & $\mathrm{~S} 2-\mathrm{S} 35$ & $70.0 \%$ \\
3 & $\mathrm{~S} 3-\mathrm{S} 36$ & $77.8 \%$ \\
4 & $\mathrm{~S} 4-\mathrm{S} 37$ & $64.7 \%$ \\
5 & $\mathrm{~S} 5-\mathrm{S} 38$ & $73.7 \%$ \\
6 & $\mathrm{~S} 6-\mathrm{S} 39$ & $80.0 \%$ \\
7 & $\mathrm{~S} 7-\mathrm{S} 40$ & $100.0 \%$ \\
8 & $\mathrm{~S} 8-\mathrm{S} 41$ & $85.7 \%$ \\
9 & $\mathrm{~S}-\mathrm{S} 42$ & $81.8 \%$ \\
10 & $\mathrm{~S} 10-\mathrm{S} 43$ & $70.0 \%$
\end{tabular}

As can be seen from Table 1, when comparing the RAPD spectra of strains extracted from the affected and intact areas of the skin of patients with hypertension ( 8 patients), the degree of genetic relatedness of the strains averaged $75.1 \pm 4.4 \% \%$, indicating that the strains belong to the same genotype. Only two patients had low and moderate genetic relatedness between strains removed from lesions and intact skin $-47.1 \%$ and 64.7 , which indicates the likelihood of different strains.

In the analysis of electrophoregrams of laboratory isolates S44-S55 extracted from intact areas of the skin of patients with severe AD, one cluster of RAPD spectra was identified: 
with the presence of fragments weighing from 200 to 2000 bp. (Fig. 5, row 2 track No. 1-11). The degree of affinity between isolates isolated from intact skin ranged from $70.6 \%$ to $100 \%$ (mean $83.1 \pm 3.5 \%$ ). Data on the comparison of RAPD spectra of laboratory strains of staphylococci extracted from the affected and intact areas of the skin of patients with severe AD are shown in Table 2.

Table 2

Comparison of fingerprints of $S$. aureus strains extracted from lesions and intact skin areas of patients with severe AD

\begin{tabular}{ccc}
\hline No. & The compared strains & The level of strains affinity \\
\hline 1 & $\mathrm{~S} 22-\mathrm{S} 44$ & $100 \%$ \\
2 & $\mathrm{~S} 23-\mathrm{S} 45$ & $94.1 \%$ \\
3 & $\mathrm{~S} 24-\mathrm{S} 46$ & $100 \%$ \\
4 & $\mathrm{~S} 25-\mathrm{S} 47$ & $100 \%$ \\
5 & $\mathrm{~S} 26-\mathrm{S} 48$ & $100 \%$ \\
6 & $\mathrm{~S} 27-\mathrm{S} 49$ & $100 \%$ \\
7 & $\mathrm{~S} 28-\mathrm{S} 50$ & $100 \%$ \\
8 & $\mathrm{~S} 29-\mathrm{S} 51$ & $94.1 \%$ \\
9 & $\mathrm{~S} 30-\mathrm{S} 52$ & $100 \%$ \\
10 & $\mathrm{~S} 31-\mathrm{S} 53$ & $100 \%$ \\
11 & $\mathrm{~S} 32-\mathrm{S} 54$ & $100 \%$ \\
12 & $\mathrm{~S} 33-\mathrm{S} 55$ & $100 \%$
\end{tabular}

As can be seen from Table 2, when comparing the RAPD spectra of strains extracted from the affected and intact areas of the skin of patients with severe AD (12 patients), the degree of genetic relatedness of the strains was $98.8 \pm 0.8 \%$, indicating that strains are identical.

In the analysis of electrophoregrams of laboratory isolates S1-S11 extracted from the skin of healthy individuals, two clusters of RAPD spectra were identified: with the presence of fragments weighing from 200 to 2000 bp. (Fig. 6, tracks No. 2-11) and 150-900 n. p. (Fig. 6, track No. 1). The total number of fragments ranged from 5 to 9 . When comparing the RAPD spectra of the first and second clusters, the degree of similarity was $46.2 \%$.

Table 3 compares the RAPD spectra of strains extracted from the skin of healthy individuals.

Table 3

Comparison of fingerprints of $S$. aureus strains removed from the skin of healthy individuals

\begin{tabular}{ccc}
\hline No. & The compared strains & The level of strains affinity \\
\hline 1 & $\mathrm{~S} 1-\mathrm{S} 2$ & $61.5 \%$ \\
2 & $\mathrm{~S} 2-\mathrm{S} 3$ & $58.8 \%$ \\
3 & $\mathrm{~S} 3-\mathrm{S} 4$ & $82.4 \%$ \\
4 & $\mathrm{~S} 4-\mathrm{S} 5$ & $82.3 \%$ \\
5 & $\mathrm{~S} 5-\mathrm{S} 6$ & $66.7 \%$ \\
6 & $\mathrm{~S} 6-\mathrm{S} 7$ & $70.6 \%$ \\
7 & $\mathrm{~S} 7-\mathrm{S} 8$ & $62.5 \%$ \\
8 & $\mathrm{~S} 8-\mathrm{S} 9$ & $53.3 \%$ \\
9 & $\mathrm{~S} 9-\mathrm{S} 10$ & $80.0 \%$ \\
10 & $\mathrm{~S} 10-\mathrm{S} 11$ & $66.7 \%$
\end{tabular}

According to Table 3, the degree of genetic affinity between strains ranged from $53.3 \%$ to $82.4 \%$, the average affinity between isolates isolated from the skin of healthy individuals was 
$68.5 \pm 3.2 \%$, indicating the absence of close genetic relatedness between the removed microorganisms, and no genotypes that were inherent in healthy skin were identified.

In the analysis of electrophoregrams of laboratory isolates S1-S12 extracted from the nasal passages of patients with severe AD, one cluster of RAPD spectra with the presence of fragments weighing from 200 to 2000 bp (Fig. 7, lanes No. 1-11) The total number of fragments ranged from 5 to 10 . When comparing RAPD-spectra, the degree of similarity ranged from $61.5 \%$ to $100 \%$, the average was $82.3 \pm 3.6 \%$. Table 4 compares the RAPD spectra of strains extracted from the nasal passages and locus morbi of patients with AD.

\section{Table 4}

Comparison of the affinity of fingerprints of S. aureus strains extracted from the lesions and nasal passages of patients with severe AD

\begin{tabular}{ccc}
\hline No. & The compared strains & The level of strains affinity \\
\hline 1 & $\mathrm{~S} 1-\mathrm{S} 22$ & $82.3 \%$ \\
2 & $\mathrm{~S} 2-\mathrm{S} 23$ & $76.9 \%$ \\
3 & $\mathrm{~S} 3-\mathrm{S} 24$ & $76.9 \%$ \\
4 & $\mathrm{~S} 4-\mathrm{S} 25$ & $92.3 \%$ \\
5 & $\mathrm{~S} 5-\mathrm{S} 26$ & $71.4 \%$ \\
6 & $\mathrm{~S} 6-\mathrm{S} 27$ & $82.3 \%$ \\
7 & $\mathrm{~S}-\mathrm{S} 28$ & $82.3 \%$ \\
8 & $\mathrm{~S} 8-\mathrm{S} 29$ & $71.4 \%$ \\
9 & $\mathrm{~S} 9-\mathrm{S} 30$ & $80.0 \%$ \\
10 & $\mathrm{~S} 10-\mathrm{S} 31$ & $75.5 \%$ \\
11 & $\mathrm{~S} 11-\mathrm{S} 32$ & $82.3 \%$ \\
12 & $\mathrm{~S} 12-\mathrm{S} 33$ & $80.0 \%$
\end{tabular}

As can be seen from Table 4, strains removed from the nasal passages had a high level of genetic affinity with strains removed from the affected areas of the skin at the level of $79.5 \pm 1.6 \%$ (from $71.4 \%$ to $92.3 \%$ ), indicating the similarity of the genotypes of $S$. aureus that were studied, and indicates the auto-origin of strains that grow on the affected and intact areas of the skin of patients.

As a result of the conducted researches it was established that the average indicator of variability of laboratory strains of $S$. aureus extracted from AD patients and referred to the most widespread cluster made $77.6 \% \pm 3.3 \%$ that testifies to high genetic affinity among these cultures. The degree of affinity of these strains with the reference culture of $S$. aureus ATCC 25923 averaged $33.6 \%$, indicating their low genetic affinity. When comparing the RAPD spectra of strains extracted from the affected and intact areas of the skin of patients with mild and moderate degree of genetic relatedness of the strains averaged $71.3 \%$, which indicates that the strains belong to the same genotype. Only one patient had a low genetic relationship between the strain removed from the lesion and intact skin $-47.1 \%$, which indicates the likelihood of different origins of the strains. When comparing the RAPD spectra of strains extracted from the affected and intact areas of the skin of patients with severe AD (12 patients), the degree of genetic relatedness of the strains was $100 \%$, indicating that the strains belong to the same genotype.

Thus, in the study of $S$. aureus strains isolated from patients with AD, no genotype was identified that would be associated with AD or the severity of its course. A high level of genetic homogeneity of strains removed from locus morbi with strains removed from the nasal passages $(79.5 \pm 1.6 \%)$ was established, which indicates the auto-origin of strains that grow on the affected and intact areas of the skin of patients. It is shown that with increasing severity of the disease, the genetic monotype of isolated pathogens increased: in patients with mild AD, 3 genetic clusters of the microorganism were identified, with moderate -2 , and with severe only one. 
In the analysis of electrophoregrams of laboratory isolates S1-S12 extracted from the affected areas of the skin of patients with mild IE, 1 cluster of RAPD spectra was isolated: with the presence of fragments weighing from 200 to 2000 bp. (Fig. 8, tracks No. 1-12), the number of obtained fragments ranged from 6 to 11 . The degree of affinity between isolates obtained from intact skin ranged from $70.6 \%$ to $88.9 \%$ (mean $80.8 \pm 2.1 \%$ ). When comparing the RAPD spectra of laboratory strains with the reference culture of S. aureus ATCC 25923, a low genetic affinity with the profiles of cultures isolated from patients (28.6\% of similarity).

In the analysis of electrophoregrams of laboratory isolates S13-S22 extracted from the affected areas of the skin of patients with moderate to severe IE, 1 cluster of RAPD spectra was isolated: with the presence of fragments weighing from 200 to 2000 bp. (Fig. 9, tracks No. 1-10), the number of obtained fragments ranged from 5 to 10 . The degree of affinity between isolates isolated from intact skin ranged from $66.7 \%$ to $100 \%$ (mean $83.1 \pm 4.0 \%$ ). When comparing the RAPD spectra of laboratory strains with the reference culture of $S$. aureus ATCC 25923, low genetic affinity with the profiles of cultures isolated from patients (30.0\% of similarity).

When analysing the electrophoregram of laboratory isolates S23-S33, 2 clusters of RAPD spectra were identified: with the presence of fragments weighing from 150 to $2000 \mathrm{bp}$. (Fig. 1, tracks No. 1, 2 and 4-11), 50-900 bp (Fig. 10, track No. 3). The total number of fragments ranged from 3 to 9 . Within the first PCR type, the degree of similarity of RAPD spectra ranged from $62.5 \%$ to $82.4 \%$ (average $76.0 \pm 2.6 \%$ ), indicating that these strains belong to one genotype. When comparing the first and second clusters, the degree of similarity was $7.1 \%$, which indicates a significant genetic difference.

Comparison of the affinity of these clusters with the reference strain of S. aureus ATCC 25923 (Fig. 1, track 11) revealed low affinity with the profile of cultures of both the first type and the second type $-22.2 \%$ and $28.6 \%$, respectively.

In the analysis of electrophoregrams of laboratory isolates S34-S43 extracted from intact areas of the skin of patients with IE, one cluster of RAPD spectra was isolated: with the presence of fragments weighing from 200 to 2000 bp. (Fig. 11, tracks No. 1-10), the number of obtained fragments ranged from 7 to 11 . The degree of affinity between isolates from intact skin was from $66.7 \%$ to $100 \%$ (average $84.0 \pm 3.9 \%$ ).

Data on the comparison of RAPD spectra of laboratory strains of staphylococci extracted from the affected and intact areas of the skin of patients with IE are shown in Table $\mathbf{5}$.

\section{Table 5}

Comparison of fingerprints of $S$. aureus strains extracted from lesions and intact areas of skin of patients with IE

\begin{tabular}{ccc}
\hline No. & The compared strains & The level of strains affinity \\
\hline 1 & $\mathrm{~S} 13-\mathrm{S} 34$ & $50.0 \%$ \\
2 & $\mathrm{~S} 14-\mathrm{S} 35$ & $51.4 \%$ \\
3 & $\mathrm{~S} 15-\mathrm{S} 36$ & $72.2 \%$ \\
4 & $\mathrm{~S} 16-\mathrm{S} 37$ & $58.8 \%$ \\
5 & $\mathrm{~S} 17-\mathrm{S} 38$ & $53.3 \%$ \\
6 & $\mathrm{~S} 18-\mathrm{S} 39$ & $70.6 \%$ \\
7 & $\mathrm{~S} 19-\mathrm{S} 40$ & $88.9 \%$ \\
8 & $\mathrm{~S} 20-\mathrm{S} 41$ & $75 \%$ \\
9 & $\mathrm{~S} 21-\mathrm{S} 42$ & $75 \%$ \\
10 & $\mathrm{~S} 22-\mathrm{S} 43$ & $77.8 \%$ \\
& & $\mathbf{6 7 . 7 \pm 4 . 2} \%$
\end{tabular}

As can be seen from Table 5, when comparing the RAPD spectra of strains extracted from the affected and intact areas of the skin of patients with IE (6 patients), the degree of genetic relatedness of the strains averaged $76.6 \%$, indicating that the strains belong to the same genotype. 
Four patients had moderate genetic relatedness between the strain removed from the lesion and intact skin at $53.4 \%$, indicating the likelihood of different strain origins. The degree of similarity of $S$. aureus RAPD spectra extracted from the affected areas of the skin of patients with IE, which were classified as the most common cluster, ranged from $62.5 \%$ to $82.4 \%$ (average $76.0 \pm 2.6 \%$ ) indicating that these strains belong to the same genotype. The degree of affinity of these strains with the reference culture of $S$. aureus ATCC 25923 averaged 27.4 $\pm 1.8 \%$, which indicates their low genetic affinity.

There are data in the foreign literature on the possibility of RAPD genotyping of $S$. aureus strains using OLP-6, OLP-11 and OLP-13 primers, but these studies concerned the typing of strains extracted from various objects, including banknotes, food, biological material of patients with infectious diseases $[8,16]$. There are no data on the use of these primers for RAPD genotyping of $S$. aureus strains isolated from patients with allergodermatoses. The obtained data are a priority.

Study limitations. The study included adult patients with allergic dermatitis diagnosed with atopic dermatitis (L 20.0) and eczema (L 30.0 - other dermatitis) according to the International Classification of Diseases 10.

Prospects for further research. Further studies include the study of correlations between phenotypic and genotypic traits of extracted pathogen isolates in order to develop algorithms for predicting the severity of marked allergic dermatitis.

\section{Conclusions}

1. In the study of RAPD spectra of $S$. aureus strains extracted from patients with AD, no genotype was identified that would be associated with this dermatosis or the severity of its course. When comparing the RAPD spectra of strains extracted from the affected and intact areas of the skin of patients with mild AD in $80.0 \%$ of patients, the degree of genetic relatedness of the strains averaged $75.1 \pm 4.4 \%$, indicating that the strains belong to the same genotype. When comparing the RAPD spectra of strains extracted from the affected areas of the skin of patients with severe AD (12 patients), the degree of genetic affinity of the strains was $98.8 \pm 0.8 \%$, indicating that the strains are identical.

2. A high level of genetic affinity of strains removed from locus morbi with strains removed from the nasal passages $(79.5 \pm 1.6 \%)$, indicating the auto-origin of strains that grow on the affected and intact areas of the skin of patients. It is shown that with increasing severity of AD, the genetic monotype of isolated pathogens increased: in patients with mild $\mathrm{AD}, 3$ genetic clusters of the microorganism were identified, with moderate -2 , and with severe only one.

3. In the study of RAPD - spectra of $S$. aureus strains isolated from patients with IE, no genotype was identified that would be associated with this dermatosis or the severity of its course. The correlation between the severity of eczema and the increase in monotype of strains for patients with IE has not been confirmed. The degree of similarity of $S$. aureus RAPD spectra extracted from the affected areas of the skin of patients with IE averaged $76.0 \pm 2.6 \%$, indicating a high genetic affinity of the strains.

4. The affinity of strains isolated from patients with IE with the reference culture of S. aureus ATCC $25923 \mathrm{u}$ was $27.4 \pm 1.8 \%$ and $52.0 \pm 5.2 \%$ for strains isolated from patients with AD, indicating their low genetic relatedness.

\section{Conflict of interest}

The authors declare there is no conflict of interest.

\section{References}

[1] Denysenko, O. I., Stepan, N. A. (2017). Klinichni rezultaty riznykh metodiv likuvannia khvorykh na ekzemu. Zhurnal dermatovenerolohii ta kosmetolohii imeni M. O. Torsuieva, 2 (38), 36-40.

[2] Grice, E. A., Kong, H. H., Renaud, G., Young, A. C., Bouffard, G. G. et. al. (2008). A diversity profile of the human skin microbiota. Genome Research, 18 (7), 1043-1050. doi: http://doi.org/10.1101/gr.075549.107

[3] Kutasevich, IA. F., Dzhoraeva, S. K., Mangusheva, V. IU. (2018). Issledovanie sostava mikrobioty kozhi i analiz ee antibiotikorezistentnosti u bolnykh allergodermatozami. Eksperimentalna i klinichna medicina, 1 (78), 101-107. 
[4] Blicharz, L., Rudnicka, L., Samochocki, Z. (2019). Staphylococcus aureus: an underestimated factor in the pathogenesis of atopic dermatitis? Advances in Dermatology and Allergology, 36 (1), 11-17. doi: http://doi.org/10.5114/ada.2019.82821

[5] Dzhoraeva, S., Sobol, N., Ivantsova, H. (2020). Phenotypical characteristics of the biological properties of staphylococci withdrawn from patients with allergic dermatitis. EUREKA: Health Sciences, 1, 15-21. doi: http://doi.org/10.21303/25045679.2020.001125

[6] Kutasevych, Y., Dzhoraeva, S., Goncharenko, V., Shcherbakova, Y., Mangusheva, V., Sobol, N., Shchegoleva, H. (2018). Research of certain pathogenic characteristics of clinical isolates of staphylococci of skin biome. EUREKA: Health Sciences, 2 , 23-30. doi: http://doi.org/10.21303/2504-5679.2018.00585

[7] Tsyhanenko, A. Ya., Tymchenko, O. M., Pokhyl, S. I. (2002). Zavdannia i shliakhy podalshoho udoskonalennia henotypuvannia zbudnykiv infektsiinykh zakhvoriuvan za dopomohoiu analizu polimorfizmu dovzhyny frahmentiv endonukleaznoi restryktsii khromosomnoi DNK. Eksperymentalna i klinichna medytsyna, 3, 79-83.

[8] Ob unifikatsii mikrobiologicheskih (bakteriologicheskih) metod ovissledovaniya, primenyaemih v kliniko-diagnosticheskih laboratoriyah lechebno-profilakticheskih uchrezhdeniy (1985). MZ SSSR, No. 535. Available at: http://www.alppp.ru/law/ zdravoohranenie--fizicheskaja-kultura-i-sport--turizm/zdravoohranenie/64/prikaz-minzdrava-sssr-ot-22-04-1985--535.html

[9] Baron, E. J., Miller, J. M., Weinstein, M. P., Richter, S. S., Gilligan, P. H., Thomson, R. B. et. al. (2013). A Guide to Utilization of the Microbiology Laboratory for Diagnosis of Infectious Diseases: 2013 Recommendations by the Infectious Diseases Society of America (IDSA) and the American Society for Microbiology (ASM)a. Clinical Infectious Diseases, 57 (4), e22-e121. doi: http://doi.org/10.1093/cid/cit278

[10] Singh, G. K., Bopanna, B. D., Rindhe, G. (2013). Molecular characterization of Staphylococcus aureus - human pathogen from clinical samples by RAPD markers. Journal of Medical Science and Clinical Research, 1 (2), 45-49.

[11] Pereira, M. S. V., Leal, N. C., Leal, T. C. A., Sobreira, M., de Almeida, A. M. P., Siqueira-Junior, J. P., Campos-Takaki, G. M. (2002). Typing of human and bovine Staphylococcus aureus by RAPD-PCR and ribotyping-PCR. Letters in Applied Microbiology, 35 (1), 32-36. doi: http://doi.org/10.1046/j.1472-765x.2002.01127.x

[12] Debnath, A., Chikkaswamy, B. K. (2015). Randomly Amplified Polymorphic DNA Assay of Methicillin Resistant Staphylococcus aureus Isolated from Clinical Samples from Bengaluru, India. International Journal of Current Microbiology and Applied Sciences, 4 (11), 342-355.

[13] Zare, S., Derakhshandeh, A., Haghkhah, M., Naziri, Z., Broujeni, A. M. (2019). Molecular typing of Staphylococcus aureus from different sources by RAPD-PCR analysis. Heliyon, 5 (8), e02231. doi: http://doi.org/10.1016/j.heliyon.2019.e02231

[14] Doan, S. Y., Savchuk, A. Y., Hladkaia, E. A. et. al. (2011). RAPD-analyz v yzuchenyy henetycheskoi heterohennosty Sorynebacterium diphtheria. Profilaktychna medytsyna, 2 (14), 39-44.

[15] Tsyhanenko, A. Ya., Tymchenko, O. M., Pokhyl, S. I. (2002). Zavdannia i shliakhy podalshoho udoskonalennia henotypuvannia zbudnykiv infektsiinykh zakhvoriuvan za dopomohoiu analizu polimorfizmu dovzhyny frahmentiv endonukleaznoi restryktsii khromosomnoi DNK. Eksperymentalna i klinichna medytsyna, 3, 79-83.

[16] Tymchenko, O. M. (2008). Molekuliarno-henetychni metody vnutrishnovydovoho epidemiolohichnoho typuvannia zbudnykiv infektsiinykh zakhvoriuvan (ohliad). Annali Mechnykovskoho ynstytuta, 3, 5-7.

[17] Shaginian, I. A. (2000). Identifikaciia i tipirovanie patogennykh bakterii: sovremennye podkhody. Vestnik RAMN, 1, $22-28$.

[18] Singh, G. K., Bopanna, B. D., Rindhe, G. (2013). Molecular characterization of Staphylococcus aureus - human pathogen from clinical samples by RAPD markers. Journal of Medical Science And clinical Research, 1 (2), 45-49.

[19] Veh, K. A., Klein, R. C., Ster, C., Keefe, G., Lacasse, P., Scholl, D. et. al. (2015). Genotypic and phenotypic characterization of Staphylococcus aureus causing persistent and nonpersistent subclinical bovine intramammary infections during lactation or the dry period. Journal of Dairy Science, 98 (1), 155-168. doi: http://doi.org/10.3168/jds.2014-8044

[20] Mobasherizadeh, S., Shojaei, H., Havaei, S. A., Mostafavizadeh, K., Davoodabadi, F., Khorvash, F. et. al. (2015). Application of the Random Amplified Polymorphic DNA (RAPD) Fingerprinting to Analyze Genetic Variation in Community Associated-Methicillin Resistant Staphylococcus Aureus (CA-MRSA) Isolates in Iran. Global Journal of Health Science, 8 (8), $185-191$. doi: http://doi.org/10.5539/gjhs.v8n8p185 